\section{Obstructive sleep apnea, detected by the Berlin Questionnaire: an associated risk factor for coronary artery disease}

\author{
Risco de apneia obstrutiva do sono detectado pelo \\ Questionário de Berlim está associado com \\ doença arterial coronariana
}

\author{
Daniela Massierer 1 \\ Denis Martinez 1 \\ Sandra Costa Fuchs 1 \\ Paulo P. Pellin 2 \\ Márcio S. Garcia 2 \\ Ana Luisa Zacharias 2 \\ Isadora F. Antunes 2 \\ Marco V. Wainstein 1 \\ Leila Beltrami Moreira 1 \\ Jorge Pinto Ribeiro 1 \\ Flavio Danni Fuchs 1
}

\footnotetext{
${ }_{1}$ Hospital de Clínicas de Porto Alegre, Universidade Federal do Rio Grande do Sul, Porto Alegre, Brasil.

2 Faculdade de Medicina Universidade Federal do Rio Grande do Sul, Porto Alegre, Brasil.

Correspondência F. D. Fuchs

Hospital de Clínicas de Porto Alegre, Universidade Federal do Rio Grande do Sul. Rua Ramiro Barcelos 2350 Porto Alegre, RS 90035-903, Brasil.

ffuchs@hcpa.ufrgs.br
}

\begin{abstract}
Obstructive sleep apnea (OSA), a risk factor for coronary artery disease, remains under diagnosed. We investigated if OSA identified by the Berlin Questionnaire (BQ) is associated with the risk of coronary artery disease. Cases were patients referred for elective coronariography. The cases were classified with significant coronary lesions (stenosis $\geq 50 \%$ in an epicardial coronary) or without significant coronary lesions. Controls were selected from a population-based sample. Positive BQ results were identified in 135 (41.2\%) of 328 cases, in contrast with 151 (34.4\%) of 439 control subjects ( $p=0.03$ ). In a multinomial logistic analysis, the risk for OSA identified by the $B Q$ was independently associated with coronary artery disease in cases with lesions of at least 50\% (OR = 1.53; 95\%CI: 1.02-2.30; $p=0.04)$. The risk from OSA identified by the BQ was higher in younger subjects (40-59 years) $(O R=1.76$; 95\%CI: 1.05-2.97; $p=0.03$ ) and in women (OR= 3.56; 95\%CI: 1.64-7.72; $p=0.001$ ). In conclusion, OSA identified by the BQ greatly increases the risks of coronary artery disease in patients having significant coronary artery lesions indicated by anangiogram, particularly in younger individuals and in women.
\end{abstract}

Coronary Artery Disease; Obstructive Sleep Apnea; Questionnaires
Obstructive sleep apnea (OSA) is highly prevalent in persons ${ }^{1}$ with coronary artery disease, a leading cause of morbidity and mortality 2 . OSA has been identified as an independent risk factor for coronary artery disease in some 3,4 but not all studies 5 . OSA and coronary artery disease share several risk factors, and it is still disputed if OSA is a direct risk for vessel damage 6 and cardiovascular disease at all 7,8. Angiographic analyses have suggested that OSA may contribute to the severity of coronary artery disease 9,10 . OSA may trigger the rupture of vulnerable plaques, leading to acute myocardial infarction 11,12. OSA has been identified as an independent predictor of angiographic and clinical outcomes in coronary artery disease, such as cardiac death, myocardial infarction and reinfarction or revascularization after percutaneous coronary intervention 13,14.

Polysomnography (PSG) is the gold standard for OSA diagnosis 15 . Nonetheless its availability is still limited worldwide. To circumvent this limitation, questionnaires have been developed to screen for OSA 16. They are easily administered, inexpensive, applicable in large surveys, and useful for screening a diagnosis of OSA. The Berlin Questionnaire (BQ) was designed to identify individuals at higher risk of having OSA in primary care. The BQ includes questions on obesity, hypertension, snoring, daytime sleepiness and fatigue 17 . We demonstrated that a positive response to the questionnaire was independently associated with resistant hypertension 18 . 
We hypothesized that an association between OSA and coronary artery disease can be detected by the BQ. As of this date, this method has not yet been employed in this setting.

\section{Methods}

This is a case-control study. Cases were patients referred for elective coronary angiography for diagnostic purposes. Patients had class I to II stable angina or had an evidence of ischemia in noninvasive testing. Patients with prior treatment of coronary artery disease by angioplasty or surgery, current or previous malignancies, chronic disabling disease, or major surgery in the last two years were excluded. Cases were additionally classified according to severity of coronary artery disease by quantitative digital angiography in patients with or without significant lesions, defined as $\geq 50 \%$ stenosis in major epicardial vessels or their branches.

Controls were selected from a populationbased study that investigated 1,858 adult residents randomly selected from the city of Porto Alegre, Rio Grande do Sul State, Brazil. Details of this study are described elsewhere 19. Among 1,210 individuals aged 40 years or older, a random sample of 439 individuals matched to the cases, by age and gender, were selected. Controls with history of cardiovascular disease (defined by a medical history of myocardial infarction, artery failure, stroke or coronary artery bypass grafting and self-reported angina pectoris) were excluded.

\section{Procedures}

Cardiovascular risk factors, socioeconomic and demographic characteristics were assessed using the same standardized questionnaire both in the control group and case individuals. Interviews were conducted by certified investigators. Skin color was defined by the referred race of the ascendants 20 . Smokers were characterized by lifetime consumption of at least 100 cigarettes, and packyears of smoking were calculated by multiplying the daily number of packs smoked and number of years of smoking 21. Abusive consumption of alcoholic beverages was defined by an average daily intake $\geq 30 \mathrm{~g}$ of ethanol for men and $\geq 15 \mathrm{~g}$ ethanol for women 22 .

Blood pressure was measured with an OMRON device, model CP-705 (OMRON Co. Ltd., Dalian, China), with the patient sitting, and the average of three measurements was used in the analyses. Hypertension was defined as systolic pressure $\geq 140 \mathrm{mmHg}$, diastolic pressure $\geq 90 \mathrm{mmHg}$ or use of blood pressure-lowering medications. Diabetes mellitus was defined by a history of a physician's diagnosis of diabetes or use of antidiabetic agents.

Anthropometric assessment was performed with the participant wearing light clothing without shoes. The average of two or three measurements was used in the analysis. Weight and height were measured in a scale to the nearest $100 \mathrm{~g}$ with a scale (model TINN 00088; Plenna S.A., São Paulo, Brazil), and height ( $\mathrm{cm}$ ) was measured maintaining the Frankfurt plane, to the nearest $0.1 \mathrm{~cm}$. Waist circumference was measured at the midpoint between the lower costal rib and superior iliac crest. Body mass index (BMI) was calculated as [weight $(\mathrm{kg}) /$ height $(\mathrm{m})^{2}$ ].

\section{Berlin Questionnaire (BO)}

Controls were interviewed during a home visit, as part of a larger study 19. Case patients answered the $\mathrm{BQ}$, read by the investigators, after catheterization. When possible, wives and husbands of the case patients and the controls helped to answering the questions.

The BQ is composed of three categories of symptoms, five questions are related to snoring and cessation of breathing in category 1 , four questions are related to daytime sleepiness in category 2; there is a question about high blood pressure and also a question about the BMI in category 3 . In category 1 and 2 , high risk was defined as persistent symptoms (> 3-4 times/week). In category 3 , high risk was defined by the presence of hypertension ( $\geq 140 / 90 \mathrm{mmHg}$ or use of medication) or a $\mathrm{BMI} \geq 30 \mathrm{~kg} / \mathrm{m}^{2}$. Patients and control subjects were classified as having high risk for OSA if scores were positive on two or more categories.

\section{Coronary angiography}

Coronary angiography was performed by transfemoral access, according to the Seldinger technique, using Axion Artis equipment (Siemens, Munich, Germany) by experienced interventional cardiologists. The diagnosis of significant lesions was established by quantitative analysis of the major epicardial vessels - branch, anterior descending artery, circumflex and right coronary artery - and branches with a diameter $\geq 3 \mathrm{~mm}$ - obtuse marginal arteries, posterolateral, first diagonal, diagonal second, apical and posterior descending. Evaluation of the images was done independently by two cardiologists and disagreements were settled by a third interventional cardiologist. Stenosis was detected, as well as the percentage of stenosis in relation to the diameter, through digital quanti- 
tative analysis. Significant coronary artery disease was defined as stenosis $\geq 50 \%$ in at least one epicardial coronary artery.

\section{Statistical analysis}

The sample size was calculated to detect an odds ratio (OR) of at least 2.0 with $\mathrm{p} \alpha=0.05$ and $80 \%$ power, assuming a prevalence of BQ positives of $35 \%$ in the controls and $50 \%$ in the cases, with a ratio between controls and cases of 2.5:1. Thus, the required sample size was 126 cases and 315 controls. In order to maintain the power in the multivariate analysis, the sample size was increased to 328 cases and 439 controls. The differences between means were compared using Student's t-test. Chi-square test was used to compare proportions. T-test and ANOVA were employed to test for differences between the cases classified with significant and non-significant coronary lesions, and controls. Odds ratios and confidence intervals for significant lesions in the high-risk BQ were calculated in a multinomial regression analysis, adjusting for age, gender, skin color, education, smoking, alcohol beverage consumption and diabetes mellitus. This method enables calculating odds ratios of a dependent-variable with more than two categories. The categories were cases with significant and non-significant lesions in the coronary angiography. Analyses were conducted using the Statistical Package for Social Sciences (version 16.0; SPSS Inc., Chicago, USA).

The study was approved by the Ethics Committee of Porto Alegre Clinics Hospital (Hospital das Clínicas de Porto Alegre) which is accredited by the Office of Human Research Protections as an Institutional Review Board. All participants signed an informed consent form.

\section{Results}

The flow chart of the selection of cases and controls is presented in the Figure 1. A total of 328 individuals referred for coronary angiography, aged 36 to 82 years, were characterized as cases and classified by the presence or absence of significant stenosis. The reasons for coronary angiography included; angina pectoris in 54.9\% of cases, a previous acute myocardial infarction (15.2\%), chest pain with positive exercise testing (16.5\%) or positive nuclear myocardial perfusion scan $(2.1 \%)$, dyspnea precipitated by exertion (3.3\%), atypical chest pain $(0.8 \%)$, abdominal pain on exertion $(0.4 \%)$ and other indications (6.5\%). Of the 328 cases, 167 had no significant lesions (<50\% stenosis) and 161 had significant lesions ( $\geq 50 \%$ stenosis) in at least one epicardial coronary artery.

Demographics and other characteristics of cases and controls are showed in Table 1. There were no significant differences between groups in distribution of gender and smoking. Cases had higher systolic and diastolic blood pressure, age, BMI, waist circumference and prevalence of hypertension and diabetes. Cases had fewer years of formal education. The proportion of individuals with a positive BQ was higher in the cases than in the controls $(41.2 \% v s .34 .4 \%$; $\mathrm{p}=0.03$ ).

In stratified analyses, the risk for OSA detected by the BQ was higher in individuals aged 40-59 years and in women (Table 2). Table 3 shows the OR for coronary artery disease when OSA is identified by the BQ, stratified by age and gender. In both crude and adjusted multinomial regression analysis, patients 40-59 years old and women identified as high risk by the BQ were more likely to have significant coronary lesions.

In Table 4, multinomial logistic analysis showed that individuals with a BQ positive result for OSA had an OR (71\% higher risk) of displaying significant coronary lesions. Adjusting for age, gender, skin color, education, smoking, alcohol beverage consumption and diabetes, the effect of a positive BQ for risk of coronary lesions was still significant $(\mathrm{OR}=1.53, \mathrm{p}=0.04)$. Hypertension and excess of adiposity, associated with OSA in the univariate analysis, were not included in the model because they are part of the BQ. Individuals without significant lesions had odds ratios not significantly different from that of the controls in any model (Table 4).

\section{Discussion}

In this case-control investigation, OSA identified by the BQ was associated with a significant risk of coronary artery disease, independent of age, gender, and other confounding factors. The association was stronger among younger individuals and women. To the best of our knowledge, this is the first demonstration of the performance of the BQ to identify the association between OSA and coronary artery diseaseas confirmed by coronary angiography. The risk of coronary artery disease associated with OSA identified by the BQ was not a factor in cases that didn't have significant coronary lesions, weakening the intensity of the association and suggesting that these individuals are similar to individuals of the same age and gender living in communities without an indication for coronary angiography. On the other hand, the risk in individuals with significant lesions has clinical implications, since the 


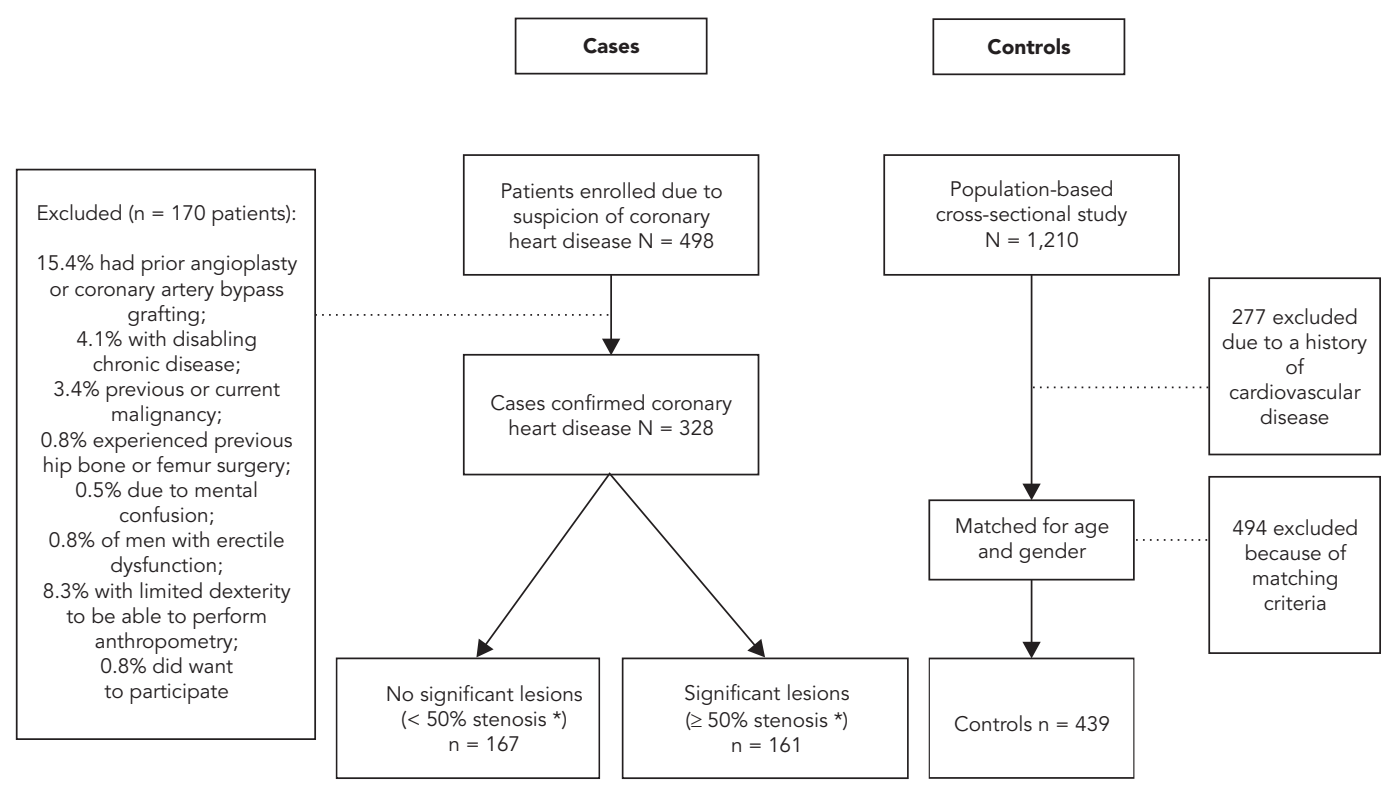

* In at least one epicardial coronary artery.

use of the BQ could optimize the referral rate for full polysomnography, an exam that is not broadly available worldwide. The confirmation of OSA would lead to treatment to prevent coronary artery disease 23,24 and the occurrence of early signs of atherosclerosis 25 .

The association between OSA and coronary artery disease has been reported in several contexts. OSA is associated with coronary risk factors $26,27,28,29,30,31$ and with known symptomatic coronary artery disease identified by angiography 32 . OSA was present in 9 of 10 patients with nocturnal angina pectoris 33 and in $37 \%$ of men and $30 \%$ of women with coronary artery disease 34 . After the first acute myocardial infarction, $65.7 \%$ of patients had an apnea-hypopnea index $\geq 15 / \mathrm{h}$ 35 . In other studies, the prevalence of OSA in patients with artery heart disease ranged from 43 to $66.4 \% 36,37,38,39$. The prevalence of a high risk of coronary artery disease associated with OSA in our survey was within these estimates. We had recently showed, in a post-hoc analysis of a smaller case-control study, that high risk for coronary artery disease associated with OSA had an odds ratio of 4.5 (1.03-19.25) for coronary artery disease 40 .

The BQ has been utilized to identify OSA risk factors in samples of individuals with other cardiac diseases and its prevalence has been similarly high. Chilukuri et al. ${ }^{41}$ reported a high risk factor of coronary artery disease associated with OSA identified by the BQ in $44 \%$ of patients with atrial fibrillation. Patients with OSA had a greater recurrence rate of atrial fibrillation after catheter arrhythmia ablation than patients without OSA. The prevalence of a high risk factor of coronary artery disease associated with OSA identified by the BQ was $80 \%$ in patients with resistant hypertension versus $44 \%$ in patients with controlled hypertension 18 . Drager et al. 42 found similar performance of the BQ in the hypertensive population.

The high risk factor of coronary artery disease associated with OSA identified by the BQ was $34.4 \%$ in the control group and was similar to reports of the high risk factor of coronary artery disease associated with OSA identified by the BQ that ranged between 26 and 37.5\% 17,26,43,44. In contrast, the prevalence of OSA identified by the $\mathrm{BQ}$ in our control population was lower than the reported by Tufik et al. 1, using PSG, in a sample of the general population (49.3\%).

Women are less likely than men to report typical snoring and symptoms of apnea 45 . There is also a tendency to delay suspicion and diagnosis of coronary artery disease in women 46 . The 
Table 1

Demographics and other characteristics of control individuals and case patients.

\begin{tabular}{|c|c|c|c|}
\hline & Controls $(n=439)$ & Cases $(n=328)$ & p-value * \\
\hline Gender & & & 0.762 \\
\hline Male & $274(62.4)$ & $209(63.7)$ & \\
\hline Female & $165(37.6)$ & $119(36.3)$ & \\
\hline Age (years) & $56.3 \pm 9.5$ & $58.3 \pm 9.2$ & 0.004 \\
\hline Skin color & & & 0.006 \\
\hline White & $327(74.5)$ & $214(65.2)$ & \\
\hline Education (years) & $8.9 \pm 5.1$ & $6.2 \pm 4.1$ & $<0.001$ \\
\hline Alcohol consumption & & & $<0.001$ \\
\hline Non-abusive & $282(64.2)$ & $301(91.8)$ & \\
\hline Abusive & $157(35.8)$ & $27(8.2)$ & \\
\hline Smoking (packs/years) & & & 0.653 \\
\hline Absent or $<20$ & $165(37.6)$ & $129(39.3)$ & \\
\hline$\geq 20$ & $274(62.4)$ & $199(60.7)$ & \\
\hline Systolic blood pressure $(\mathrm{mmHg})$ & $131.6 \pm 23.2$ & $139.6 \pm 22.2$ & $<0.001$ \\
\hline Diastolic blood pressure $(\mathrm{mmHg})$ & $80.6 \pm 12.8$ & $82.6 \pm 13.3$ & 0.034 \\
\hline Hypertension & & & $<0.001$ \\
\hline Yes & $210(47.8)$ & $263(80.2)$ & \\
\hline No & $229(52.2)$ & $65(19.8)$ & \\
\hline Diabetes mellitus & & & 0.001 \\
\hline Yes & $51(11.6)$ & 65 (19.9) & \\
\hline No & $388(88.4)$ & $261(80.1)$ & \\
\hline BMI $\left(\mathrm{kg} / \mathrm{m}^{2}\right)$ & $26.9 \pm 4.86$ & $28.5 \pm 4.9$ & $<0.001$ \\
\hline Waist circumference & $92.5 \pm 13.3$ & $95.4 \pm 11.2$ & 0.002 \\
\hline High risk in $\mathrm{BO}$ & $151(34.4)$ & $135(41.2)$ & 0.033 \\
\hline
\end{tabular}

BMI: body mass index; BQ: Berlin Questionnaire.

Note: data are presented as number (\%) or mean \pm standard deviation.

* The differences between means and differences in proportions were compared using Student's t-test and chi-square test respectively.

Table 2

Comparison of obstructive sleep apnea syndrome risk estimated using Berlin Questionnaire (BQ) in cases and controls, stratified by gender and age-groups.

\begin{tabular}{|c|c|c|c|c|}
\hline \multirow[t]{3}{*}{ High risk } & \multirow[t]{2}{*}{ Controls $(n=439)$} & \multicolumn{2}{|c|}{ Cases $(n=328)$} & \multirow[t]{3}{*}{$p$-value } \\
\hline & & $\begin{array}{l}\text { No significant lesion } \\
\qquad(n=167)\end{array}$ & $\begin{array}{l}\text { Significant lesion } \\
\quad(n=161)\end{array}$ & \\
\hline & n (\%) & n (\%) & n (\%) & \\
\hline \multicolumn{5}{|l|}{ Age (years) } \\
\hline $40-59$ & $85(29.8)$ & $37(39.4)$ & $48(49.5)$ & 0.015 \\
\hline $60-90$ & $66(42.9)$ & $22(30.1)$ & $28(43.8)$ & 0.07 \\
\hline \multicolumn{5}{|l|}{ Gender } \\
\hline Men & $110(40.1)$ & $46(36.2)$ & $36(43.9)$ & 0.5 \\
\hline Women & $41(24.8)$ & $13(32.5)$ & $40(50.6)$ & $<0.001$ \\
\hline
\end{tabular}

Note: no significant lesion: $<50 \%$ stenosis in at least one epicardial coronary artery; significant lesion: $\geq 50 \%$ stenosis. 
Odds ratios $(\mathrm{OR})$ and $95 \%$ confidence intervals $(95 \% \mathrm{Cl})$ in multinomial regression analysis of risk of Berlin Questionnaire $(\mathrm{BQ})$ associated with coronary artery disease.

\begin{tabular}{|c|c|c|c|c|}
\hline & \multicolumn{2}{|c|}{ Unadjusted OR $(95 \% \mathrm{Cl})$} & \multicolumn{2}{|c|}{ Adjusted OR $(95 \% \mathrm{Cl})$} \\
\hline & No significant lesion & Significant lesion & No significant lesion & Significant lesion \\
\hline \multicolumn{5}{|c|}{$40-59$ years $(n=476)$} \\
\hline Low risk & 1.00 & 1.00 & 1.00 * & 1.00 * \\
\hline High risk & $1.53(0.94-2.48)$ & $2.31(1.44-3.70)$ & $1.21(0.73-2.02)$ & $1.76(1.05-2.97)$ \\
\hline p-value & 0.09 & 0.001 & 0.5 & 0.03 \\
\hline \multicolumn{5}{|c|}{$60-90$ years $(n=291)$} \\
\hline Low risk & 1.00 & 1.00 & 1.00 * & 1.00 * \\
\hline High risk & $0.58(0.32-1.04)$ & $1.04(0.58-1.87)$ & $0.59(0.29-1.08)$ & $1.28(0.65-2.51)$ \\
\hline$p$-value & 0.07 & 0.9 & 0.08 & 0.5 \\
\hline \multicolumn{5}{|c|}{ Men $(n=483)$} \\
\hline Low risk & 1.00 & 1.00 & $1.00 * \star$ & $1.00 * *$ \\
\hline High risk & $0.85(0.55-1.31)$ & $1.17(0.71-1.92)$ & $0.74(0.47-1.18)$ & $1.08(0.64-1.82)$ \\
\hline $\mathrm{p}$-value & 0.5 & 0.5 & 0.2 & 0.8 \\
\hline \multicolumn{5}{|c|}{ Women $(n=284)$} \\
\hline Low risk & 1.00 & 1.00 & 1.00 ** & 1.00 ** \\
\hline High risk & $1.46(0.69-3.08)$ & $3.10(1.76-5.46)$ & $1.66(0.64-3.30)$ & $3.56(1.64-7.72)$ \\
\hline $\mathrm{p}$-value & 0.3 & $<0.001$ & 0.3 & 0.001 \\
\hline
\end{tabular}

Note: no significant lesion: $<50 \%$ stenosis in at least one epicardial coronary artery; significant lesion: $\geq 50 \%$ stenosis.

* OR adjusted for: gender, skin color, education, smoking, alcohol consumption and diabetes;

** OR adjusted for: age, skin color, education, smoking, alcohol consumption and diabetes.

The association of Berlin Questionnaire (BQ) with coronary artery disease according to confounding factors.

\begin{tabular}{|c|c|c|c|c|c|}
\hline & \multirow{3}{*}{$\begin{array}{c}\text { Controls } \\
(n=439) \\
\text { OR }(95 \% \mathrm{Cl})\end{array}$} & \multicolumn{4}{|c|}{ Cases } \\
\hline & & \multicolumn{2}{|c|}{ No significant lesion $(n=167)$} & \multicolumn{2}{|c|}{ Significant lesion $(n=161)$} \\
\hline & & OR $(95 \% \mathrm{Cl})$ & p-value & OR $(95 \% \mathrm{Cl})$ & $\mathrm{p}$-value \\
\hline $\mathrm{BO}$ (risk, 1) & 1.00 & $1.04(0.72-1.51)$ & 0.8 & $1.71(1.18-2.46)$ & 0.004 \\
\hline Model 1: BQ + age (years) & 1.00 & $1.01(0.69-1.47)$ & 1.0 & $1.69(1.17-2.45)$ & 0.005 \\
\hline Model 2: Model 1+ male gender & 1.00 & $0.96(0.66-1.41)$ & 0.9 & $1.77(1.22-2.57)$ & 0.003 \\
\hline Model 3: Model 2 + skin color (white) & 1.00 & $0.96(0.65-1.40)$ & 0.8 & $1.76(1.21-2.56)$ & 0.003 \\
\hline Model 4: Model 3 + education (years) & 1.00 & $0.93(0.63-1.36)$ & 0.7 & $1.62(1.10-2.38)$ & 0.01 \\
\hline Model 5: Model 4 + smoking (pack-years) & 1.00 & $0.93(0.63-1.36)$ & 0.7 & $1.62(1.10-2.39)$ & 0.01 \\
\hline Model 6: Model $5+$ alcoholic consumption (abusive) & 1.00 & $0.88(0.59-1.31)$ & 0.5 & $1.53(1.02-2.30)$ & 0.04 \\
\hline Model 7: Model 6 + diabetes mellitus & 1.00 & $0.87(0.58-1.31)$ & 0.5 & $1.53(1.02-2.30)$ & 0.04 \\
\hline
\end{tabular}

OR: odds ratio; $95 \% \mathrm{Cl}$ : $95 \%$ confidence interval.

Note: no significant lesion: $<50 \%$ stenosis in at least one epicardial coronary artery; significant lesion: $\geq 50 \%$ stenosis. 
lower suspicion of OSA identified by the BQ in women, was associated with the higher prevalence of abnormal angiograms in women (85.9 vs. $73.7 \%$ in men) and may explain the higher risk for coronary artery diseasein women with a positive BQ than that identified in this survey. The gender difference in OSA prevalence is negligible after the age of 60 years 2,47 . The OSA identified by the $\mathrm{BQ}$ and suspicion of higher risk for significant coronary artery disease in individuals aged 40-59 years age group suggests that OSA is more important in younger individuals. At older ages, other risk factors for coronary heart disease may prevail in the causation of atherosclerosis,making the risk added by OSA in elderly individuals undetectable by the BQ.

Our study has limitations that deserve attention. The $\mathrm{BQ}$ is a screening test for the high risk of OSA and should not replace a full OSA investigation ${ }^{48}$. On the other hand, the use of the BQ as screening for OSA is feasible and may help to increase the diagnosis of OSA in patients with suspected coronary artery disease 49 . Since controls were not submitted to coronary angiogra- phy, the possibility they had subclinical coronary atherosclerosis remains and could be a measurement bias. Nonetheless, this possibility is unlikely, since controls never had a suspicion of having coronary artery disease (the main criterion for being a case in our investigation). The lack of evaluation of lipid profile in cases and controls is a potential source of bias, but there was no reason to suspect that the prevalence of lipid disorders was any different between individuals with and without OSA. The case-control design precludes establishing the temporal association. OSA may be the cause of coronary artery disease and vice-versa. The bulk of evidence, including longitudinal studies, suggests that the first option is more plausible.

In conclusion, the high risk factor of coronary artery disease associated with OSA identified by the BQ predicts significant coronary artery lesions, particularly in middle-aged patients and in women. The use of the BQ in patients with suspicion of coronary artery disease may increase the diagnosis and treatmentof OSA, preventing the clinical manifestations of disease.

\begin{abstract}
Resumo
Síndrome da apneia obstrutiva do sono (SAOS), fator de risco para doença arterial coronariana, permanece subdiagnosticada. Investigou-se se o risco de SAOS pelo Questionário de Berlim (QB) associa-se com doença arterial coronariana. Casos foram pacientes encaminhados para coronariografia eletiva, classificados em casos com lesão significativa (estenose $\geq 50 \%$ ) ou sem lesões significativas. Controles foram selecionados em amostra populacional. QB foi positivo em 135 (41,2\%) de 328 casos, em contraste com 151 (34,4\%) de 439 controles $(p=0,03)$. Em análise logística multinomial, o risco de SAOS identificado pelo QB associou-se com doença arterial coronariana exclusivamente nos casos com lesões de pelo menos 50\% (OR: 1,53; IC95\%: 1,022,30; $p=0,04)$. Em indivíduos com lesões significativas, o risco de SAOS pela QB foi maior entre os que têm 40-59 anos (OR: 1,76; IC95\%: 1,05-2,97; $p=0,03$ ) e em mulheres (OR: 3,56; IC95\%: 1,64-7,72; $p=0,001$ ). Em conclusão, alto risco para a SAOS identificados pela QB associa-se a risco de lesões coronarianas significativas na angiografia, particularmente em indivíduos mais jovens e em mulheres.
\end{abstract}

Doença da Artéria Coronariana; Apnéia do Sono Tipo Obstrutiva; Questionários

\section{Contributors}

D. Massierer coordinated data collection, collaborated with the data analysis and prepared the first draft of this manuscript. J. P. Ribeiro and M. V. Wainstein performed the angiographies, participated in the interpretation of results and preparation of this manuscript. L. B. Moreira participated in the analysis of results and preparation of this manuscript. P. P. Pellin, M. S. Garcia, I. F. Antunes and A. L. Zacharias were responsible for data collection, prepared draft versions of this manuscript and gave final approval for this version of the manuscript. S. C. Fuchs, D. Martinez and F. D. Fuchs designed the study, supervised the analysis and prepared the draft and final versions of this manuscript.

\section{Acknowledgments}

We would like to thank the CNPq-INCT-IATS, CAPES and FIPE-HCPA for their financial support. 


\section{References}

1. Tufik S, Santos-Silva R, Taddei JA, Bittencourt LR. Obstructive sleep apnea syndrome in the Sao Paulo Epidemiologic Sleep Study. Sleep Med 2010; 11:441-6.

2. Yusuf S, Reddy S, Ounpuu S, Anand S. Global burden of cardiovascular diseases: part I: general considerations, the epidemiologic transition, risk factors, and impact of urbanization. Circulation 2001; 104:2746-53.

3. Lüthje L, Andreas S. Obstructive sleep apnea and coronary artery disease. Sleep Med Rev 2008; 12: 19-31.

4. Sorajja D, Gami AS, Somers VK, Behrenbeck TR, Garcia-Touchard A, Lopez-Jimenez F. Independent association between obstructive sleep apnea and subclinical coronary artery disease. Chest 2008; 133:927-33.

5. Gottlieb DJ, Yenokyan G, Newman AB, O'Connor GT, Punjabi NM, Quan SF, et al. Prospective study of obstructive sleep apnea and incident coronary heart disease and heart failure: the sleep heart health study. Circulation 2010; 122:352-60.

6. Drager LF, Bortolotto LA, Lorenzi MC, Figueiredo AC, Krieger EM, Lorenzi-Filho G. Early signs of atherosclerosis in obstructive sleep apnea. Am J Respir Crit Care Med 2005; 172:613-8.

7. Pack AI, Gislason T. Obstructive sleep apnea and cardiovascular disease: a perspective and future directions. Prog Cardiovasc Dis 2009; 51:434-51.

8. Hla KM, Young T, Finn LA, Peppard PE, Kinsey TJ, Ende D. Electrocardiographically indicated cardiovascular disease in sleep-disordered breathing. Sleep Breath 2008; 12:251-8.

10. Turmel J, Sériès F, Boulet L-P, Poirier P, Tardif JC, Rodés-Cabeau J, et al. Relationship between atherosclerosis and the sleep apnea syndrome: an intravascular ultrasound study. Int J Cardiol 2009; 132:203-9.

11. Shah NA, Yaggi HK, Concato J, Mohsenin V. Obstructive sleep apnea as a risk factor for coronary events or cardiovascular death. Sleep Breath 2010; 14:131-6.

12. Kuniyoshi FH, Garcia-Touchard A, Gami AS, Romero-Corral A, van der Walt C, Pusalavidyasagar S, et al. Day-night variation of acute myocardial infarction in obstructive sleep apnea. J Am Coll Cardiol 2008; 52:343-6.

13. Yumino D, Tsurumi Y, Takagi A, Suzuki K, Kasanuki H. Impact of obstructive sleep apnea on clinical and angiographic outcomes following percutaneous coronary intervention in patients with acute coronary syndrome. Am J Cardiol 2007; 99:26-30.

14. Peker Y, Kraiczi H, Hedner J, Löth S, Johansson A, Bende M. An independent association between obstructive sleep apnea and coronary artery disease. Eur Respir J 1999; 14:179-84.

15. Sleep-related breathing disorders in adults: recommendations for syndrome definition and measurement techniques in clinical research. The report of an American Academy of Sleep Medicine Task Force. Sleep 1999; 22:667-89.

16. Pouliot Z, Peters M, Neufeld H, Kryger MH. Using self-reported questionnaire data to prioritize patients for polysomnography. Sleep 1997; 20:232-6.
17. Netzer NC, Stoohs RA, Netzer CM, Clark K, Strohl KP. Using the Berlin Questionnaire to identify patients at risk for the sleep apnea syndrome. Ann Intern Med 1999; 131:485-91.

18. Gus M, Gonçalves SC, Martinez D, Abreu Silva EO, Moreira LB, Fuchs SC, et al. Risk for obstructive sleep apnea by Berlin Questionnaire, but not daytime sleepiness, is associated with resistant hypertension: a case-control study. Am J Hypertens 2008; 21:832-5.

19. Fuchs SC, Moreira LB, Camey SA, Moreira MB, Fuchs FD. Clustering of risk factors for cardiovascular disease among women in Southern Brazil: a population-based study. Cad Saúde Pública 2008; 24 Suppl 2:S285-93.

20. Fuchs SC, Guimarães SM, Sortica C, Wainberg F, Dias KO, Ughini M, et al. Reliability of race assessment based on the race of the ascendants: a crosssectional study. BMC Public Health 2002; 2:1.

21. Bernaards CM, Twisk JW, Snel J, Van Mechelen W, Kemper HC. Is calculating pack-years retrospectively a valid method to estimate life-time tobacco smoking? A comparison between prospectively calculated pack-years and retrospectively calculated pack-years. Addiction 2001; 6:1653-61.

22. Moreira LB, Fuchs DF, Moraes RS, Bredemeier M, Cardozo S, Fuchs SC, et al. Alcoholic beverage consumption and association factors in Porto Alegre, a southern Brazilian city: a population-based survey. J Stud Alcohol 1996; 57:253-9.

23. Marin JM, Carrizo SJ, Vicente E, Agusti AG. Longterm cardiovascular outcomes in men with obstructive sleep apnoea-hypopnoea with or without treatment with continuous positive airway pressure: an observational study. Lancet 2005; 365:1046-53.

24. Cassar A, Morgenthaler TI, Lennon RJ, Rihal CS, Lerman A. Treatment of obstructive sleep apnea is associated with decreased cardiac death after percutaneous coronary intervention. J Am Coll Cardiol 2007; 50:1310-4.

25. Drager LF, Bortolotto LA, Figueiredo AC, Krieger EM, Lorenzi GF. Effects of continuous positive airway pressure on early signs of atherosclerosis in obstructive sleep apnea. Am J Respir Crit Care Med 2007; 176:706-12.

26. Peppard PE, Young T, Palta M, Skatrud J. Prospective study of the association between sleep-disordered breathing and hypertension. N Engl J Med 2000; 342:1378-84.

27. Schafer H, Koehler U, Ewig S, Hasper E, Tasci S, Lüderitz B. Obstructive sleep apnea as a risk marker in coronary artery disease. Cardiology 1999; 92: 79-84.

28. Reichmuth KJ, Austin D, Skatrud JB, Young T. Association of sleep apnea and type II diabetes: a population-based study. Am J Respir Crit Care Med 2005; 172:1590-5.

29. Borgel J, Sanner BM, Bittlinsky A, Keskin F, Bartels NK, Buechner N, et al. Obstructive sleep apnoea and its therapy influence high-density lipoprotein cholesterol serum levels. Eur Respir J 2006; 27:121-7.

30. Parish JM, Somers VK. Obstructive sleep apnea and cardiovascular disease. Mayo Clin Proc 2004; 79:1036-46. 
31. Shamsuzz aman AS, Gersh BJ, Somers VK. Obstructive sleep apnea: implications for cardiac and vascular disease. JAMA 2003; 290:1906-14.

32. Hayashi M, Fujimoto K, Urushibata K, Uchikawa S, Imamura H, Kubo K. Nocturnal oxygen desaturation correlates with the severity of coronary atherosclerosis in coronary artery disease. Chest 2003; 124:936-41.

33. Franklin KA, Nilsson JB, Sahlin C, Näslund U. Sleep apnoea and nocturnal angina. Lancet 1995; 345:1085-7.

34. Mooe T, Rabben T, Wiklund U, Franklin KA, Eriksson P. Sleep-disordered breathing in women: occurrence and association with coronary artery disease. Am J Med 1996; 101:251-6.

35. Lee CH, Khoo SM, Tai BC, Chong EY, Lau C, Than Y, et al. Obstructive sleep apnea in patients admitted for acute myocardial infarction. Prevalence, predictors, and effect on microvascular perfusion. Chest 2009; 135:1488-95.

36. Nakashima H, Katayama T, Takagi C, Amenomori K, Ishizaki M, Honda Y, et al. Obstructive sleep apnoea inhibits the recovery of left ventricular function in patients with acute myocardial infarction. Eur Heart J 2006; 27:2317-22.

37. Davignon J, Ganz P. Role of endothelial dysfunction in atherosclerosis. Circulation 2004; 109(23 Suppl 1):III27-32.

38. Lorenzi-Filho G, Drager LF. Obstructive sleep apnea and atherosclerosis: a new paradigm. Am J Respir Crit Care Med 2007; 175:1219-21.

39. Savransky V, Nanayakkara A, Li J, Bevans S, Smith PL, Rodriguez A, et al. Chronic intermittent hypoxia induces atherosclerosis. Am J Respir Crit Care Med 2007; 175:1290-7.

40. Martinez D, Silva RP, Klein C, Fiori CZ, Massierer D, Cassol CM, et al. High risk for sleep apnea in the Berlin questionnaire and coronary artery disease. Sleep Breath 2012; 16:89-94.

41. Chilukuri K, Dalal D, Marine JE, Scherr D, Henrikson CA, Cheng A, et al. Predictive value of obstructive sleep apnoea assessed by the Berlin Questionnaire for outcomes after the catheter ablation of atrial fibrillation. Europace 2009; 11:896-901.
42. Drager LF, Genta PR, Pedrosa RP, Nerbass FB, Gonzaga CC, Krieger EM, et al. Characteristics and predictors of obstructive sleep apnea in patients with systemic hypertension. Am J Cardiol 2010; 105:1135-9.

43. Netzer N, Hoegel J, Loube D, Netzer CM, Hay B, Alvarez-Sala R, et al. Prevalence of symptoms and risk of sleep apnea in primary care. Chest 2003; 124:1406-14.

44. Hiestand DM, Britz P, Goldman M, Phillips B. Prevalence of symptoms and risk of sleep apnea in the US population: results from the national sleep foundation sleep in America 2005 poll. Chest 2006; 130:780-6.

45. Redline S, Kump K, Tishler PV, Browner I, Ferrette V. Gender differences in sleep disordered breathing in a community-based sample. Am J Resp Crit Care Med 1994; 149:722-6.

46. Douglas PS, Ginsburg GS. The evaluation of chest pain in women. N Engl J Med 1996; 334:1311-5.

47. Ye L, Pien GW, Weaver TE. Gender differences in the clinical manifestations of obstructive sleep apnea. Sleep Med 2009; 10:1075-84.

48. Young T, Evans L, Finn L, Palta M. Estimation of the clinically diagnosed proportion of sleep apnea syndrome in middle-aged men and women. Sleep 1997; 20:705-6.

49. Somers VK, White DP, Amin R, Abraham WT, Costa F, Culebras A, et al. Sleep apnea and cardiovascular disease: an American Heart Association/American College of Cardiology Foundation Scientific Statement from the American Heart Association Council for High Blood Pressure Research Professional Education Committee, Council on Clinical Cardiology, Stroke Council, and Council On Cardiovascular Nursing. In collaboration with the National Heart, Lung, and Blood Institute National Center on Sleep Disorders Research (National Institutes of Health). Circulation 2008; 118:1080-111.

Submitted on 01/Dec/2011

Final version resubmitted on 16/Feb/2012 Approved on 02/Mar/2012 